\title{
Changes in depressive symptoms and correlates in HIV+ people at An Hoa Clinic in Ho Chi Minh City, Vietnam
}

\author{
Van-Anh N. Huynh', Kien G. To ${ }^{1 *}$, Dung Van Do', Quyen G. To² and Mai T H Nguyen ${ }^{3}$
}

\begin{abstract}
Background: Understanding of depression among Vietnamese people living with HIV (PLWH) is limited. This longitudinal study examines changes in depressive symptoms and identifies its correlates among people living with HIV under antiretroviral therapy at An Hoa Clinic.

Methods: People living with HIV $\geq 18$ years and undergoing antiretroviral therapy for $\geq 3$ months were eligible. Those at final AIDS stage, too ill, or illiterate were excluded due to their inability to complete the self-administered questionnaire. One researcher was present in the clinic for a month inviting PLWH to participate. Data were collected from 242 PLWH at baseline (T1) and 234 after three months (T2). Depressive symptoms was measured by the Center for Epidemiologic Studies Depression Scale (CESD). Social relationship was measured using questions created by World Health Organization. Generalized Estimating Equations were used examining changes in depressive symptoms with CESD cut-off $<16 / \geq 16$ (mild depression) and cut-off $<23 / \geq 23$ (major depression).
\end{abstract}

Results: Model 1 (CESD cut-off $<16 / \geq 16$ ) showed that participants were not more likely to have depressive symptoms at $\mathrm{T} 2$ compared to $\mathrm{T} 1(\mathrm{OR}=1.15, p>0.05)$. Those with a co-morbidity were more likely to have depressive symptoms than those without a co-morbidity $(\mathrm{OR}=1.76, p<0.05)$. Those with higher social relationship scores were less likely to have depressive symptoms than those with lower scores $(\mathrm{OR}=0.76, p<0.001)$. Model 2 (CESD cut-off $<23 / \geq 23$ ) showed that participants were more likely to have major depressive symptoms at T2 compared to T1 ( $\mathrm{OR}=1.6$, $p<0.01)$ and those with higher social relationship score were less likely to have major depressive symptoms than those with lower scores (OR $=0.73, p<0.001)$.

Conclusions: People living with HIV were not more likely to have depressive symptoms $(<16 / \geq 16)$ but were more likely to have major depressive symptoms $(<23 / \geq 23)$ at T2 vs. T1. Social relationship was found to be strongly associated with depressive symptoms. Associations between age, individual income status, and co-morbidity with depressive symptoms were not decisive. Gender, ethnicity, education, religion, marriage, household economy, and adherence were not correlates.

Keywords: HIV, Depression, Correlate, ART, Vietnam

\footnotetext{
* Correspondence: kiengiato@gmail.com

${ }^{1}$ Faculty of Public Health, University of Medicine and Pharmacy, 217 Hong

Bang, District 5, Ho Chi Minh City, Vietnam

Full list of author information is available at the end of the article
} 


\section{Background}

Depression is one of the most common mental health diagnoses among people living with HIV/AIDS (PLWH) [1]. The lifetime prevalence of depression among PLWH was estimated between $22 \%$ - 45\% [2]. The 12-month prevalence of major depression was $22 \%$ in a nationally representative cohort of PLWH receiving care in the U.S. [3]. Although the rate among PLWH may or may not be different from other adults in the same community, it seemed to be lower for the general population $[1,4,5]$. The prevalence rate for major depression was $6.6 \%$ among adults participating in a U.S. representative household survey [6].

Studies on changes in depressive symptoms found mixed results. Although one study found that the mood was stable regardless of illness progression [7], another study showed that depression decreased over a two-year period after receiving ART [8]. Others showed that depression did not change until the period of 12-18 months before AIDS diagnosis when depression started increasing significantly [9-11].

Depression was found to be associated with HIV progression and mortality among PLWH [12-15]. In addition, PLWH with depression were more likely to have poor medication adherence [16-19]. Those with depression and poor adherence had a mortality risk of six times higher than those without depression [20]. Effective treatment of depression also improved adherence to antiretroviral therapy (ART) [21]. Other correlates of depression included age, gender, substance abuse, perceptions of HIV related stigma, social support and social isolation [1, 22-27].

Vietnam is a Southeast Asian country with over 90 million people. It is estimated that 197,335 people were living with HIV/AIDS in 2011 and 263,317 in 2015 [28]. Because HIV is usually linked to drug use and commercial sex workers $[29,30]$, which are illegal and culturally unacceptable in Vietnam, PLWH are likely to experience mental health problems, particularly depression, due to stigma and discrimination [31]. Social support and access to mental health care for PLWH are also insufficient in Vietnam [32-34].

Understanding about depression among PLWH in Vietnam is limited. In our literature review, we found only two cross-sectional studies on depression among PLWH in Vietnam. One showed that depression prevalence among HIV-infected men over a month was $18.7 \%$, which seems to be much higher than the general population of Vietnamese men [35]. The second article found an inverse association between ART adherence and depression [36].

This study, therefore, aims to address this gap by (1) examining changes in depression symptoms among PLWH at An Hoa clinic in Ho Chi Minh city (HCMc),
Vietnam; and (2) identifying correlates of depression. Findings from this study will improve knowledge about depression among PLWH in Vietnam and help design effective interventions.

\section{Methods}

\section{Study design and population}

This longitudinal study was conducted from November 2012 to April 2013 at An Hoa Clinic of Center for Preventive Medicine in District 6, HCMC, Vietnam. PLWH who were 18 years or older; undergoing ART for $\geq 3$ months; and agreed to participate were eligible. Those at final AIDS stage, too ill, or illiterate were excluded due to their inability to complete the self-administered questionnaire.

One researcher stayed at the clinic during operating hours for one month and approached PLWH who visited the clinic for services, in order to screen them for eligibility and invite them to participate in the study. PLWH were given information about the study and written consent forms were collected if they agreed to participate. During the month, the researcher approached 255 of 1260 PLWH registered in the clinic. Of these participants, two were illiterate, one was at end stage of AIDS; and two were not receiving ART. Of $250 \mathrm{PLWH}$ who agreed to participate, two subsequently died, four were incarcerated, and two later withdrew at the first administration. Therefore, the final sample size at baseline was 242. Because our resources were limited and two previous studies showed a period of three month follow-up appropriate to see changes in depressive symptoms [37, 38], data were collected at baseline (T1) and after three months (T2) from T1. The study was approved by the Research Ethics Committee, University of Medicine and Pharmacy, Ho Chi Minh City and the Clinic Administrative Board.

\section{Measurement}

Self-administered questionnaires were provided to the participants when they visited the clinic. Record review and pill counts were used along with self-reports to determine adherence.

\section{Dependent variable}

Depression was measured by the Center for Epidemiologic Studies Depression Scale (CESD). CESD was created in 1977 and widely used to measure depression in communities [39, 40]. Particularly, it was validated among Vietnamese [40]. CESD measures nine domains of depression defined by the American Psychiatric Association [41] including Sadness, Loss of interest, Appetite, Sleep, Thinking/concentration, Guilt, Tired, Movement, and Suicidal ideation. It is comprised of 20 items, each of which is rated as $0=$ "Rarely or none of the time 
( $<1$ day)", 1 = "Some or a little of the time (1-2 days)", $2=$ "Occasionally or a moderate amount of time (3-4 days)", and $3=$ "Most or all of the time (5-7 days)". Four positive items have the scores reversed. As such, the total score ranges from 0 to 60 . Two categorical variables were created as "possible depression" or "mild depressive symptoms" where the cut-off point is $\geq /<16$; and "probable depression" or "major depression" where the cut-off point is $\geq /<23$ [39]. However, we only used the terms "mild depression" and "major depression" for consistency. Cronbach's alpha for T1 and T2 were 0.87 and 0.89 which showed strong internal consistency reliability.

\section{Independent variables}

\section{Social relationships among PLWH}

Social Relationships Were measured by four questions created by the World Health Organization (WHO-QOL BREF) [42]. The first one is: "To what extent do you feel accepted by the people you know?" and five responses are "Not at all", "A little", "Moderately", "Mostly", and "Completely". The other three are "How satisfied are you with your personal relationships?", "How satisfied are you with your sex life?", and "How satisfied are you with the support you get from your friends?" and the responses are "Very dissatisfied", "Dissatisfied", "Neither satisfied nor dissatisfied", "Satisfied", and "Very satisfied". The score for each question is from one (negative) to five (positive). The total score, therefore, ranges from 4 to 20 . Cronbach's alpha for $\mathrm{T} 1$ and $\mathrm{T} 2$ were 0.66 and 0.76 which showed good internal consistency reliability.

\section{Medication adherence}

A definition of medication adherence by the Vietnam Ministry of Health was modified to measure adherence [43]. First, two yes-no questions were asked: (i) "During the last month, have you ever given your medication to others?"; and (ii) "During the last month, have you ever forgotten to take your medication?" Second, although self-reports of adherence are fairly accurate [44], returned pills were counted to cross-validate. A mismatch between self-reports and pill counts resulted in an answer of "Yes" for the question (ii). Third, the appointment date was checked to see whether the participant was late, i.e., did not re-visit the clinic at the appointed date or within the following day. An answer of "Yes" to any of these resulted in coding of poor adherence.

Other independent variables including co-morbidity, age, gender, ethnicity, education, marital status, religion, individual income status, and household economy were self-reported. Co-morbidity was "Yes" if a respondent had at least one of these diseases including tuberculosis, hepatitis B or C, cardiovascular disease, or kidney diseases. Age groups were "18-30 years", "31-40 years", and "41-59 years". Gender was "Female" or "Male". Ethnicity was "Kinh people" (main ethnic group in Vietnam) or "Others". Participants' levels of education were grouped into "Below Grade 10" or " $\geq$ Grade 10". Responses for marital status were grouped into "Living with a spouse/ partner" or "Others". Responses for having a religion were "Yes" or "No". Individual income status was responded as "Regular", "Irregular", or "No income". Household economy was categorized as "Economically disadvantaged" or "Not economically disadvantaged".

\section{Data analysis}

Data were entered using Epidata 3.1 software. Analyses were performed with the use of SAS software, v9.4. Frequencies and percentages were generated for categorical variables. Means and standard deviations were generated for continuous variables. Chi-square test was used to see whether there were differences in demographic characteristics of the samples at two time points. Two models with CESD cut-off of 16 "mild depression" (model 1) and 23 "major depression" (model 2) were run. Although the first cut-off $(<16 / \geq 16)$ was traditional and used in most research with CES-D, the second cut-off $(<23 / \geq 23)$ was also used because somatic depressive symptoms on CES-D can overlap with HIV-related disease symptoms (e.g., poor appetite) and inflate CES-D scores [45]. Potential correlates were included in these two models and odd ratios were reported for each correlates. TukeyKramer adjustment was applied when conducting multiple comparison for two variables: age and individual income status. All $p$-values are two tailed and $p$-values of $<0.05$ were considered statistically significant.

Generalized Estimating Equations (GEE) were used to examine changes in depressive symptoms. GEE is a suggested method to analyze correlated longitudinal data [46]. It provides consistent and robust estimation of parameters' standard errors and can be applied to different types of outcome variables (e.g., continuous, dichotomous, and count). GEE can account for unequal intervals among waves and for missing data in longitudinal studies.

\section{Results}

\section{Characteristics of the sample}

At baseline, the average age of participants was 33 years, ranging from 18 to 59 years; about $62 \%$ were from $31-40$ years (Table 1). Female made up $26.86 \%$ of the sample. A majority were "Kinh people" (85.54\%); did not go to senior high school (78.10\%); and had a religion (88.43\%). About half were living with a spouse $(52.89 \%)$; and had a comorbidity (51.65\%). A quarter $(24.79 \%)$ had no income. Over one-third (40.08\%) lived in economically disadvantaged household. About $70.66 \%$ adhered to treatment. The mean of the social relationship score was 12.33. Of 242 participants, $61.98 \%$ (150 participants) had depression 
Table 1 Characteristics of the samples

\begin{tabular}{|c|c|c|c|c|}
\hline & \multicolumn{2}{|c|}{$\mathrm{T} 1(n=242)$} & \multicolumn{2}{|c|}{$\mathrm{T} 2(n=234)$} \\
\hline & $\mathrm{N}$ & Mean (SD) or \% & $\mathrm{N}$ & Mean (SD) or \% \\
\hline \multicolumn{5}{|l|}{ Age } \\
\hline $18-30$ & 67 & $27.69 \%$ & 67 & $28.63 \%$ \\
\hline $31-40$ & 151 & $62.40 \%$ & 143 & $61.11 \%$ \\
\hline $41-59$ & 24 & $9.92 \%$ & 24 & $10.26 \%$ \\
\hline Gender (Female) & 65 & $26.86 \%$ & 64 & $27.35 \%$ \\
\hline Ethnicity (Kinh people) & 207 & $85.54 \%$ & 200 & $85.47 \%$ \\
\hline Education (Below Grade 10) & 189 & $78.10 \%$ & 183 & $78.21 \%$ \\
\hline Religion (Yes) & 214 & $88.43 \%$ & 209 & $89.32 \%$ \\
\hline Marital status (Live with spouse) & 128 & $52.89 \%$ & 123 & $52.56 \%$ \\
\hline \multicolumn{5}{|l|}{ Individual income status } \\
\hline Regular & 106 & $43.80 \%$ & 108 & $46.15 \%$ \\
\hline Irregular & 76 & $31.40 \%$ & 69 & $29.49 \%$ \\
\hline No income & 60 & $24.79 \%$ & 57 & $24.36 \%$ \\
\hline Household economy (economically disadvantaged) & 97 & $40.08 \%$ & 86 & $36.75 \%$ \\
\hline Co-morbidity (Yes) & 125 & $51.65 \%$ & 125 & $53.42 \%$ \\
\hline Adherence (Yes) & 171 & $70.66 \%$ & 194 & $82.91 \%$ \\
\hline Social relationship score & 242 & $12.33(2.78)$ & 234 & $12.33(2.91)$ \\
\hline CESD mean score (SD) & 242 & $19.91(10.33)$ & 234 & $20.56(10.23)$ \\
\hline \multicolumn{5}{|l|}{ CESD cut-off $(\geq 16)$} \\
\hline Yes & 150 & $61.98 \%$ & 148 & $63.25 \%$ \\
\hline No & 92 & $38.02 \%$ & 86 & $36.75 \%$ \\
\hline \multicolumn{5}{|l|}{ CESD cut-off ( $(\geq 23)$} \\
\hline Yes & 84 & $34.71 \%$ & 99 & $42.31 \%$ \\
\hline No & 158 & $65.29 \%$ & 135 & $57.69 \%$ \\
\hline
\end{tabular}

CESD the Center for Epidemiologic Studies Depression scale SD Standard Deviation

and $34.71 \%$ (84 participants) had major depression. CESD mean score was 19.91 .

The number of participants at T1and T2 was, respectively, 242 and 234. Chi-square test showed that differences in demographic characteristics at the two time points were not significant $(p=0.904$ for gender, $p=0.959$ for age groups, $p=0.983$ for ethnicity, $p=0.978$ for education level, and $p=0.759$ for religion).

\section{Changes in depressive symptoms and correlates}

Model 1 with CESD cut-off of 16 showed that participants were not more likely to have depressive symptoms at T2 compared to T1 $(\mathrm{OR}=1.15, p>0.05)$. Model 2 with CESD cut-off of 23 showed that odds of having major depression at T2 compared to T1 was $1.6(p<0.01)$ (Table 2).

Model 1 found two correlates with depression, comorbidity and social relationship. Those with a comorbidity were more likely to have depressive symptoms than those without a co-morbidity $(\mathrm{OR}=1.76, p<0.05)$. Those with higher social relationship score were less likely to have depressive symptoms than those with lower scores $(\mathrm{OR}=0.76, p<0.001)$. Model 2 found that only social relationship was associated with depression. Those with higher social relationship score were less likely to have major depression than those with lower scores $(\mathrm{OR}=0.73, p<0.001)$. In both models, depression was not significantly associated with other variables such as age, gender, and medication adherence $(p>0.05)$.

\section{Discussion}

The findings showed that PLWH were not more likely to have depressive symptoms $(\mathrm{CESD} \geq 16)$ at $\mathrm{T} 2 \mathrm{com}$ pared to baseline (model 1) but were more likely to have major depression $(C E S D \geq 23)$ at $\mathrm{T} 2$ compared to baseline (model 2). This may suggest that progression from not having depression $(\mathrm{CESD}<16)$ to having depression was not as significant as the progression from having mild to major depression. One possible explanation may be because those who already had mild depression were more likely to live in an unfavorable environment where 
Table 2 GEE for binomial models with CESD cut-off of 16 and 23

\begin{tabular}{|c|c|c|c|c|}
\hline & \multicolumn{2}{|c|}{ Model 1 - CESD $(<16 / \geq 16)$} & \multicolumn{2}{|c|}{ Model 2 - CESD $(<23 / \geq 23)$} \\
\hline & OR & $95 \% \mathrm{Cl}$ & OR & $95 \% \mathrm{Cl}$ \\
\hline Time 2 vs. Time 1 & 1.15 & $(0.86,1.53)$ & 1.60 & $(1.13,2.24)^{* *}$ \\
\hline \multicolumn{5}{|l|}{ Age } \\
\hline (18-30) vs. $(31-40)$ & 0.87 & $(0.43,1.72)$ & 0.63 & $(0.32,1.24)$ \\
\hline (18-30) vs. (41-59) & 0.72 & $(0.24,2.22)$ & 0.38 & $(0.14,1.06)$ \\
\hline (31-40) vs. (41-59) & 0.83 & $(0.30,2.33)$ & 0.60 & $(0.28,1.30)$ \\
\hline Female vs. Male & 1.06 & $(0.60,1.88)$ & 1.21 & $(0.70,2.11)$ \\
\hline Kinh people vs. others & 0.72 & $(0.33,1.54)$ & 0.69 & $(0.38,1.28)$ \\
\hline Below vs. Above grade 10 & 1.32 & $(0.76,2.26)$ & 1.11 & $(0.62,1.99)$ \\
\hline Religion (Yes vs. No) & 0.80 & $(0.38,1.69)$ & 1.01 & $(0.46,2.19)$ \\
\hline Live with spouse vs. not & 1.02 & $(0.64,1.64)$ & 1.10 & $(0.69,1.75)$ \\
\hline \multicolumn{5}{|l|}{ Individual income status } \\
\hline Regular vs. irregular & 1.08 & $(0.58,2.04)$ & 0.63 & $(0.34,1.20)$ \\
\hline Regular vs. no income & 0.84 & $(0.41,1.72)$ & 0.57 & $(0.29,1.10)$ \\
\hline Irregular vs. no income & 0.78 & $(0.35,1.72)$ & 0.89 & $(0.46,1.72)$ \\
\hline Household economy (Not economically disadvantaged vs. disadvantaged) & 0.69 & $(0.45,1.04)$ & 0.90 & $(0.55,1.48)$ \\
\hline Co-morbidity (Yes vs. No) & 1.76 & $(1.15,2.70)^{*}$ & 1.23 & $(0.77,1.98)$ \\
\hline Social relationship (one unit difference) & 0.76 & $(0.69,0.82)^{* * *}$ & 0.73 & $(0.66,0.81)^{* * *}$ \\
\hline Adherence (Yes vs. No) & 0.73 & $(0.47,1.16)$ & 0.69 & $(0.44,1.09)$ \\
\hline
\end{tabular}

Note: the models included all covariates

Probability of having depression was modeled ${ }^{*} p<0.05$ * $^{* *} p<0.01$; *** $p<0.001$

$O R$ odds ratio, CESD the Center for Epidemiologic Studies Depression scale, GEE Generalized Estimating Equations

stigma, lack of mental health services, and insufficient support were more popular than those without depression (i.e., CESD < 16). As environmental effects accumulated, depression symptoms increased. However, this is speculative since data on environment, especially social environment, were not collected. In addition, although it is possible that the effect of previous exposure to the questionnaire may influence responses at T2 (e.g., PLWH responded with more depression at $\mathrm{T} 2$ expecting to receive more support), it may not be plausible because differences in depression was not significant in model 1.

Although reliable population comparisons are not available, high prevalence of major depression (34.31\%) in the study sample likely indicates that interventions are needed to prevent and control depression among PLWH.

Despite that women were found more likely than men to suffer depression in the general population [47], the association was less consistent among PLWH [1, 48-50]. In this study, women seemed to have more depression although the association was insignificant. It is worth noting that women made up only $26 \%$ of the sample, and so the statistical power to detect differences between the sexes may be limited.

Medication adherence was not associated with depression in this study. This is not consistent with other studies which found that depression was associated with poorer adherence $[16,17,36]$. This may be due to PLWH's reactivity, i.e., trying to improve adherence, as they may think that they were under a close supervision when participating in the study. However, it is also worth noting that this study used a stricter definition of adherence by which remembering to take medication was not the only criterion. PLWH needed to revisit the clinic on the appointment date or the next day at the latest. As such, the finding may not be comparable to other studies.

Having a co-morbidity seems to be associated with greater likelihood of depression. Although the association was only significant in model 1 (CESD $<16 / \geq 16$ ), the direction of the effect was the same in model 2 (ORs $>1)$. The effect of co-morbidity on depression is plausible due to the impact of deteriorating physical and mental health and the stress of cost and side-effects related to treatment medication for co-morbidities.

Although depression can be effectively treated among PLWH [51, 52], interventions should focus not only on treating depression but also treating other comorbidities. In addition, the finding that social relationship was the strongest correlate with depression in this study emphasized the importance of addressing psychosocial needs of PLWH. Improving social relationship should be included as an essential strategy in future interventions. 
Although our study had an appropriate design, used validated measurement tools, and had an adequate sample size, it has some limitations. First, this study was conducted in only one clinic so generalizability was limited. Second, depression were self-reported so they may not be as accurate as clinical diagnosis. However, as the same self-reported tool was used at both T1 and T2, the effect of this bias would be limited. Third, although the instruments were validated, recall bias is possible in self-reported data. Fourth, as depression treatment was not controlled for, it is possible that some received depression treatment elsewhere during the three-month study period. However, the chance was minimal because depression care was very limited in Vietnam [34]. Mental health services, even in big cities such as Hanoi and Ho Chi Minh city, do not focus on depression but mainly on schizophrenia, bipolar disorder, and epilepsy [34]. Finally, since this is an observational study without a comparison group, many factors which could affect depression could not be fully controlled.

\section{Conclusion}

PLWH were not more likely to have depression $(<16 / \geq 16)$ at T2 compared with baseline but more likely to have major depression $(<23 / \geq 23)$ at T2 compared with baseline. Social relationship was found to be strongly associated with depression. Associations between age, individual income status, and co-morbidity were not decisive. Gender, ethnicity, education, religion, marriage, household economy, and adherence were not correlates.

Our study was a response to a call for more studies on HIV and depression in Asian countries [53]. It contributes to understanding of depression among PLWH receiving ART in Asia, and particularly in Vietnam. Our findings emphasize the need for interventions addressing mental health among PLWH in Vietnam. This study can be useful in designing and building effective interventions to prevent and control depression. Future research should include larger and more diverse samples to increase generalizability; control effects associated with other factors such as previous exposure to the questionnaire; improve depression diagnosis by clinical assessment; and evaluate severity of co-morbidities to increase the strength of conclusions.

\section{Acknowledgement}

The authors thank the reviewers and Associate Professor Emeritus Trude Bennett University of North Carolina for reviewing the manuscript and for their valuable comments.

\section{Funding}

No funding was provided.

\section{Authors' contribution}

ANVH, KGT, DVD designed the study. ANVH collected the data. KGT drafted the manuscript. QGT did the analysis. MTHN supported data collection. KGT, ANVH, DVD, QGT, MTHN contributed to interpretation of data. ANVH, DVD, QGT, MTHN critically reviewed the manuscript for important intellectual content. All authors read and approved the final manuscript.

\section{Authors' information \\ Authors' information was provided in the cover page of the manuscript.}

\section{Competing interests}

The authors declare that they have no competing interests.

\section{Ethics approval and consent to participate}

The study was approved by the Research Ethics Committee, University of Medicine and Pharmacy, Ho Chi Minh City and the Clinic Administrative Board. Written consent forms were collected if participants agreed to participate.

\section{Consent for publication}

Not applicable.

\section{Author details}

${ }^{1}$ Faculty of Public Health, University of Medicine and Pharmacy, 217 Hong Bang, District 5, Ho Chi Minh City, Vietnam. ${ }^{2}$ Faculty of Health, School of Exercise and Nutrition Sciences, Queensland University of Technology, Victoria Park Road Kelvin Grove, Brisbane, Queensland 4059, Australia. ${ }^{3}$ Center for Preventive Medicine in District 6, A14/1 Ba Hom, cu xa Phu Lam D, P13, Quan 6, Tp.HCM, Vietnam.

Received: 16 February 2016 Accepted: 10 December 2016

Published online: 21 January 2017

\section{References}

1. Rabkin JG. HIV and depression: 2008 review and update. Current HIV/AIDS Reports. 2008;5(4):163-71.

2. Penzak SR, Reddy YS, Grimsley SR. Depression in patients with HIV infection. Am J Health Syst Pharm. 2000;57(4):376-89.

3. Orlando M, Burnam MA, Beckman R, Morton SC, London AS, Bing EG, et al. Re-estimating the prevalence of psychiatric disorders in a nationally representative sample of persons receiving care for HIV: results from the HIV cost and services utilization study. Int J Methods Psychiatr Res. 2002;11(2):75-82.

4. Simoni JM, Safren SA, Manhart LE, Lyda K, Grossman Cl, Rao D, et al. Challenges in addressing depression in HIV research: assessment, cultural context, and methods. AIDS Behav. 2011;15(2):376-88.

5. Kessler RC, Gruber M, Hettema JM, Hwang I, Sampson N, Yonkers KA. Comorbid major depression and generalized anxiety disorders in the National Comorbidity Survey follow-up. Psychol Med. 2008;38(3):365.

6. Kessler RC, Berglund P, Demler O, et al. The epidemiology of major depressive disorder: Results from the national comorbidity survey replication (ncs-r). JAMA. 2003;289(23):3095-105.

7. Rabkin JG, Goetz RR, Remien RH, Williams JB, Todak G, Gorman JM. Stability of mood despite HIV illness progression in a group of homosexual men. Am J Psychiatry. 1997;154(2):231-8.

8. Judd FK, Cockram AM, Komiti A, Mijch AM, Hoy J, Bell R. Depressive symptoms reduced in individuals with HIV/AIDS treated with highly active antiretroviral therapy: a longitudinal study. Aust N Z J Psychiatry. 2000;34(6):1015-21.

9. Lyketsos C, Hoover D, Guccione M, Treisman G, Dew M, Wesch J, et al. Depressive symptoms over the course of HIV infection before AIDS. Soc Psychiatry Psychiatr Epidemiol. 1996;31(3-4):212-9.

10. Lyketsos CG, Hoover DR, Guccione M, Dew MA, Wesch JE, Bing EG, et al. Changes in depressive symptoms as AIDS develops. Am J Psychiatry. 1996; 153(11):1430-7.

11. Hoover DR, Saah A, Bacellar H, Murphy R, Visscher B, Metz S, et al. The progression of untreated HIV-1 infection prior to AIDS. Am J Public Health 1992:82(11):1538-41.

12. Cook JA, Grey D, Burke J, Cohen MH, Gurtman AC, Richardson JL, et al. Depressive symptoms and AIDS-related mortality among a multisite cohort of HIV-positive women. Am J Public Health. 2004;94(7):1133-40.

13. Ickovics JR, Hamburger ME, Vlahov D, Schoenbaum EE, Schuman P, Boland RJ, et al. Mortality, CD4 cell count decline, and depressive symptoms among HIV-seropositive women. JAMA. 2001;285(11):1466-74. 
14. Bouhnik A-D, Préau M, Vincent E, Carrieri MP, Gallais H, Lepeu G, et al. Depression and clinical progression in HIV-infected drug users treated with highly active antiretroviral therapy. Antivir Ther. 2005;10(1):53-61.

15. Page-Shafer K, Delorenze GN, Satariano WA, Winkelstein W. Comorbidity and survival in HIV-infected men in the San Francisco Men's Health Survey. Ann Epidemiol. 1996;6(5):420-30.

16. Berger-Greenstein JA, Cuevas CA, Brady SM, Trezza G, Richardson MA, Keane TM. Major depression in patients with HIV/AIDS and substance abuse. AIDS Patient Care STDS. 2007;21(12):942-55.

17. Safren SA, Radomsky AS, Otto MW, Salomon E. Predictors of psychological well-being in a diverse sample of HIV-positive patients receiving highly active antiretroviral therapy. Psychosomatics. 2002;43(6):478-85.

18. Achappa B, Madi D, Bhaskaran U, Ramapuram JT, Rao S, Mahalingam S. Adherence to antiretroviral therapy among people living with HIV. N Am J Med Sci. 2013;5(3):220-3.

19. Kong MC, Nahata MC, Lacombe VA, Seiber EE, Balkrishnan R. Association between race, depression, and antiretroviral therapy adherence in a lowincome population with HIV infection. J Gen Intern Med. 2012;27(9):1159-64.

20. Lima VD, Geller J, Bangsberg DR, Patterson TL, Daniel M, Kerr T, et al. The effect of adherence on the association between depressive symptoms and mortality among HIV-infected individuals first initiating HAART. Aids. 2007; 21(9):1175-83.

21. Sin NL, Dimatteo MR. Depression Treatment Enhances Adherence to Antiretroviral Therapy: a Meta-Analysis. Ann Behav Med. 2014;47(3):259-269.

22. Stober DR, Schwartz JA, McDaniel JS, Abrams RF. Depression and HIV disease: Prevalence, correlates and treatment. Psychiatric Annals. 1997;27(5): 372-77.

23. Emlet CA. An examination of the social networks and social isolation in older and younger adults living with HIV/AIDS. Health Soc Work. 2006;31(4):299-308.

24. Flowers P, Davis M, Hart G, Rosengarten M, Frankis J, Imrie J. Diagnosis and stigma and identity amongst HIV positive Black Africans living in the UK. Psychol Health. 2006:21(1):109-22.

25. Catz SL, Gore-Felton C, McClure JB. Psychological distress among minority and low-income women living with HIV. Behav Med. 2002;28(2):53-60.

26. Mizuno Y, Purcell DW, Dawson-Rose C, Parsons JT, team TS. Correlates of depressive symptoms among HIV-positive injection drug users: the role of social support. AIDS Care. 2003;15(5):689-98.

27. Li L, Lee S-J, Thammawijaya P, Jiraphongsa C, Rotheram-Borus MJ. Stigma, social support, and depression among people living with HIV in Thailand. AIDS Care. 2009:21(8):1007-13.

28. National committee for AIDS drugs and prostitution prevention and control. Viet Nam AIDS Response Progress Report 2012. Retrieved 12/12/2016, from http://unaids.org.vn/en/viet-nam-aids-responseprogress-report-2012/.

29. Malta M, Magnanini MM, Mello MB, Pascom ARP, Linhares Y, Bastos FI. HIV prevalence among female sex workers, drug users and men who have sex with men in Brazil: A Systematic Review and Meta-analysis. BMC Public Health. 2010;10(1):1-16.

30. Subcommittee for HIV/AIDS Surveillance. HIV sentinel surveillance report. Hanoi: Ministry of Health; 2003.

31. Thi MDA, Brickley DB, Vinh DTN, Colby DJ, Sohn AH, Trung NQ, et al. A qualitative study of stigma and discrimination against people living with HIV in Ho Chi Minh City, Vietnam. AIDS Behav. 2008;12(1):63-70.

32. Loenzien Md. Implementation of a continuum of care for people living with HIV/AIDS in Hanoi (Vietnam). In: MDG Congress Tlemcen, Millenium Development Goals, Health-related goals, Tlemcen, Algeria, October, 2009. 2009: John Libbey Eurotext; 2009. p. 141-148.

33. Duchesne B, Franchi O. Mental health distress among HIV-infected male drug users and female sex partners in Vietnam. In: 6th IAS Conference on HIV Pathogenesis, Treatment and Prevention. Rome: International AIDS Society; 2011.

34. Ngo VK, Weiss B, Lam T, Dang T, Nguyen T, Nguyen MH. The Vietnam multicomponent collaborative care for depression program: development of depression care for low-and middle-income nations. J Cogn Psychother. 2014:28(3):156.

35. Esposito CA, Steel Z, Gioi TM, Huyen TTN, Tarantola D. The prevalence of depression among men living with HIV infection in Vietnam. Am J Public Health. 2009;99(S2):S439-44.

36. Do HM, Dunne MP, Kato M, Pham CV, Nguyen KV. Factors associated with suboptimal adherence to antiretroviral therapy in Viet Nam: a crosssectional study using audio computer-assisted self-interview (ACASI). BMC Infect Dis. 2013;13(1):1-9.
37. Pischke CR, Frenda S, Ornish D, Weidner G. Lifestyle changes are related to reductions in depression in persons with elevated coronary risk factors. Psychol Health. 2010;25(9):1077-100.

38. Solberg L, Fischer L, Wei F, Rush W, Conboy K, Davis T, et al. A CQI intervention to change the care of depression: a controlled study. Eff Clin Pract. 2001:4(6):239-49.

39. Radloff LS. The CES-D scale a self-report depression scale for research in the general population. Appl Psychol Meas. 1977;1(3):385-401.

40. Tran TV, Ngo D, Conway K. A Cross-cultural measure of depressive symptoms among Vietnamese Americans. Soc Work Res. 2003;27(1):56.

41. American Psychiatric Association. Diagnostic and statistical manual of mental disorders: DSM-IV: Amer Psychiatric Pub Inc; 1994.

42. World Health Organization. WHOQOL-HIV BREF 2002. Retrieved 12/12/2016, from http://www.who.int/mental_health/publications/whoqol/en/.

43. Vietnam Ministry of Health. Guidance for care and treatment in HIV/AIDS. Hanoi: Medicine Publisher; 2005. p. 66.

44. Chesney MA. Factors affecting adherence to antiretroviral therapy. Clin Infect Dis. 2000;30(Supplement 2):S171-6.

45. Kalichman SC, Rompa D, Cage M. Distinguishing between overlapping somatic symptoms of depression and HIV disease in people living with HIVAIDS. J Nerv Ment Dis. 2000;188(10):662-70

46. Ghisletta P, Spini D. An introduction to generalized estimating equations and an application to assess selectivity effects in a longitudinal study on very old individuals. J Educ Behav Stat. 2004;29(4):421-37.

47. Nolen-Hoeksema S. Gender differences in depression. Curr Dir Psychol Sci. 2001:10(5):173-6.

48. Vosvick M, Martin LA, Smith NG, Jenkins SR. Gender differences in HIVrelated coping and depression. AIDS Behav. 2010;14(2):390-400.

49. Turner BJ, Laine C, Cosler L, Hauck WW. Relationship of Gender, Depression, and Health Care Delivery With Antiretroviral Adherence in HIV-infected Drug Users. J Gen Intern Med. 2003;18(4):248-57.

50. Haug NA, Sorensen J, Lollo N, Gruber V, Delucchi K, Hall S. Gender differences among HIV-positive methadone maintenance patients enrolled in a medication adherence trial. AIDS Care. 2005;17(8):1022-9.

51. Olatunji BO, Mimiaga MJ, O Cleirigh C, Safren SA. A review of treatment studies of depression in HIV. Top HIV Med. 2006;14(3):112.

52. Markowitz JC, Rabkin JG, Perry SW. Treating depression in HIV-positive patients. Aids. 1994;8(4):403-12.

53. Sherr L, Clucas C, Harding R, Sibley E, Catalan J. HIV and depression-a systematic review of interventions. Psychol Health Med. 2011;16(5):493-527.

\section{Submit your next manuscript to BioMed Central and we will help you at every step:}

- We accept pre-submission inquiries

- Our selector tool helps you to find the most relevant journal

- We provide round the clock customer support

- Convenient online submission

- Thorough peer review

- Inclusion in PubMed and all major indexing services

- Maximum visibility for your research

Submit your manuscript at www.biomedcentral.com/submit 